
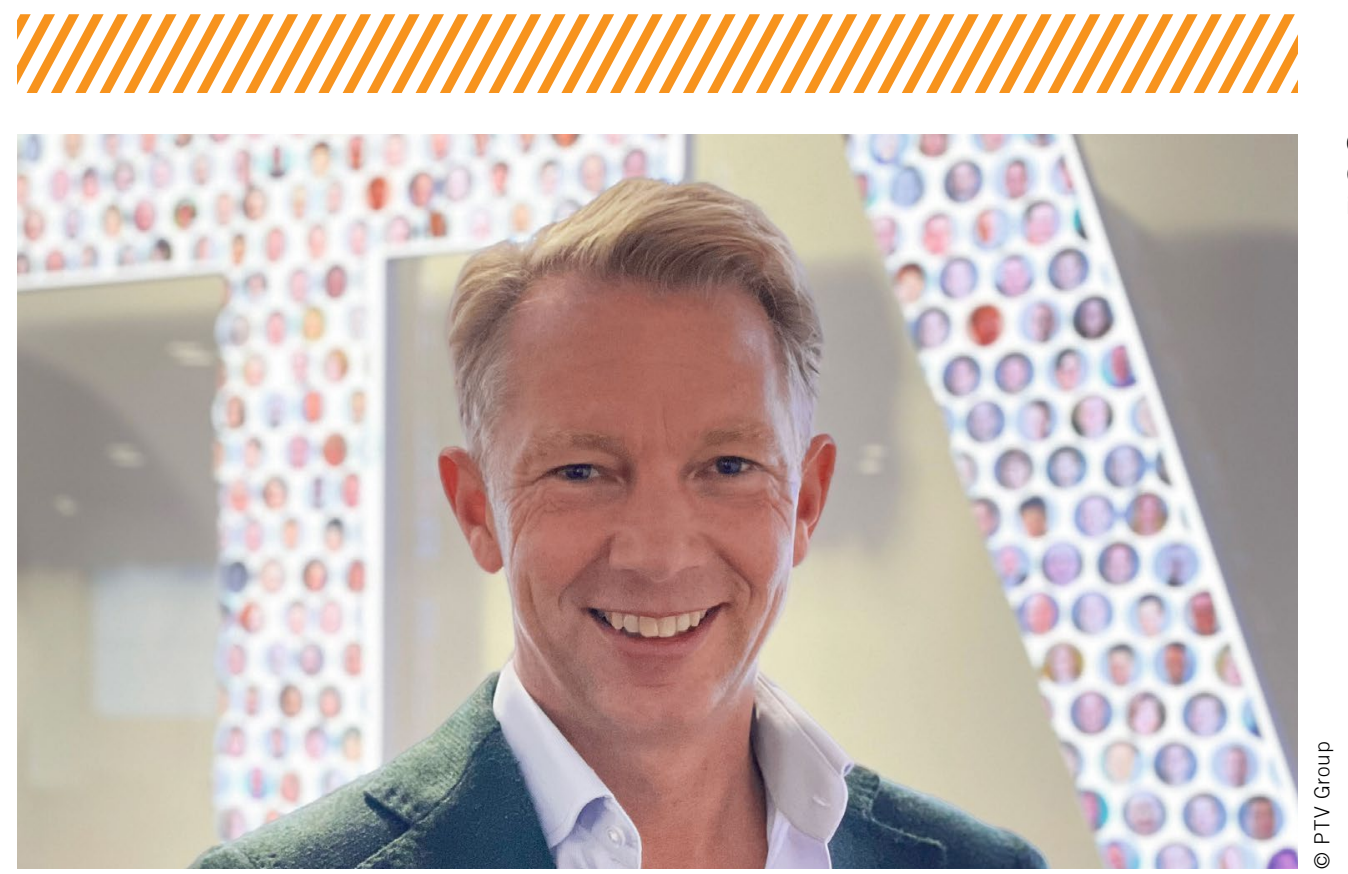

Christian U. Haas

CEO der PTV Group

in Karlsruhe

\title{
Bitte warten: Ausbau der deutschen Ladeinfrastruktur
}

Die E-Mobilität boomt, wie 2021 in Deutschland deutlich zu spüren war und die kontinuierlich steigenden Absatzzahlen zeigen. Dank staatlicher Förderungen und attraktiver Leasingraten werden die E-Autos für immer mehr Menschen erschwinglich. Und auch die deutschen Autobauer haben ihren Fokus inzwischen verstärkt auf das E-Auto ausgerichtet. So kündigten dieses Jahr gleich mehrere Hersteller das Verbrenner-Aus für das nächste Jahrzehnt an. Der schnelle Hochlauf der E-Mobilität gilt als eines der Schlüsselelemente für die Verkehrswende. Was diesen aber immer noch ausbremst, ist der stockende Ausbau der Ladeinfrastruktur. Zwar stehen in Deutschland mittlerweile über 25.000 öffentliche Ladestationen - jedoch sind diese ungleichmäßig verteilt, und es fehlt an ausreichend Schnellladern.

Ein Problem, das nicht nur der Bund erkannt hat - um bis 2025 mindestens 50.000 Ladepunkte vorweisen zu können, fördert Deutschland den Ausbau mit 500 Millionen Euro. Auch klassische Stromversorger, Stadtwerke, Automobilhersteller bis hin zu Ölkonzernen investieren in E-Ladeinfrastruktur. Warum geht es also trotz immenser Wachstumschancen, Förderung und Investitionswillen nur so langsam voran? Ein Grund ist sicherlich, dass die Planung häufig zu wenig systematisch erfolgt. Die optimalen Standorte für rentable Ladesäulen zu finden und die richtigen Investitionsentscheidungen zu treffen, ist eine Herausforderung mit vielen Fragestellungen: Wie viele Menschen werden in einer bestimmten Region auf E-Autos umsteigen und wann? Wo werden sie das Fahrzeug laden; zu Hause, am Arbeitsplatz, an öffentlichen Säulen? Wie viele Ladepunkte werden benötigt und was sind die besten Standorte? Gibt es Points-ofInterest oder bestehende Ladepunkte in der Nähe?

Simulationsmodelle, die Daten wie Mobilität und Soziodemografie berücksichtigen, helfen dabei, demografische Muster zu verstehen und so zu erfassen, wie und wohin die Menschen fahren. Durch das Durchspielen von verschiedenen Szenarien im virtuellen Umfeld lässt sich abschätzen, wie Elektrofahrzeuge in naher oder weiterer Zukunft genutzt werden, und der Bedarf an Lademöglichkeiten prognostizieren. Neben der Bedarfs- und Standortanalyse ist ein weiterer Faktor entscheidend für eine erfolgreiche Planung: Elektrofahrzeuge benötigen ein stabiles, ausreichend starkes Stromnetz. Schnelllader kommen auf bis zu $360 \mathrm{~kW}$. Die Wahl der falschen Standorte für Ladesäulen kann schnell zu hohen Erschließungskosten führen. Im britischen Projekt „Charge“, an dem wir mit dem Energieversorger ScottishPower gearbeitet haben, haben wir erstmals Verkehrs- und Stromnetzplanung zusammengebracht. Daten über Stromnetzkapazitäten flossen in unser Verkehrsmodell ein. So konnten wir analysieren, wie sich die Nutzung von E-Fahrzeugen entwickeln wird und was dies für das Stromnetz bedeutet. In unseren verkehrsbelasteten Städten können Elektrofahrzeuge einen wichtigen Beitrag zur Luftreinhaltung leisten. Gerade weil dort viele Menschen auf öffentliche Ladepunkte angewiesen sind, muss das E-Ladenetz aber schnell ausgebaut werden. Durch effektive Datennutzung kann Simulationssoftware zu einem wertvollen Instrument für die systematische und effiziente Planung werden. 